\title{
A Computer Aided System for Incorporating the Effects of Rains in Scheduling Planning
}

\author{
Sy-Jye Guo \\ Associate Professor, Dept. of Civil Engineering, National Taiwan University, \\ Taipei, Taiwan, Email address: sjguo@ce.ntu.edu.tw
}

\begin{abstract}
Traditional scheduling software such as P3, OPENPLAN, and Microsoft Project have been widely used for schedule planning for various construction projects. However, these software do not employ the effects of rains in the scheduling process. Thus, two identical projects would yield the same total project duration even though the weather conditions in two construction sites are totally different. A computer aided system was developed to incorporate the effects of rains in schedule planning. This scheduling system incorporates the MS-Project with built-in macro program to link with a weather data base that contains the distribution of rains for the past 30 years in each county of Taiwan. Once the user locates the construction site and specifies the start date of the project, a proper amount of schedule delays due to the distribution and effects of rains would be yielded and combined with norain basis to achieve the final completion date. This scheduling system incorporates the historical data of raining pattern in the scheduling process and yields a more applicable and reliable result for schedule planning.
\end{abstract}

\section{Introduction}

Traditional scheduling software such as P3, OPENPLAN, and Microsoft Project have been widely used for schedule planning for various construction projects. However, these softwares do not employ the effects of rains in the scheduling process. Thus, two identical projects with the same network logic and activities would yield the same total project duration even though the weather conditions in the two construction sites are totally different. Moreover, the start date of the construction should also impact the final completion date of the project due to the distribution of rains in a year. In other words, two identical projects with different start dates of construction should yield different completion dates even though the construction sites are in the same location.

For example, the rain can be a significant impact for exterior wall finishing in building construction. If this activity is scheduled in the dry season, it can be completed in one month. However, if the start date of the project is shifted for one season, then the exterior wall finishing may be shifted to the raining season. In this case, it may take at least two months to complete the exterior wall finishing. On the other hand, the location of the construction site would certainly yield different raining seasons and thus result in different project completion date. To resolve these problems, the purpose of this study is set up to develop a computer aided system for schedule planning which incorporates the effects of rains in the scheduling process.

\section{Schedule impact of rains}

Traditionally, an experienced scheduler should consider and estimate the effects of rains in the schedule planning process. However, in situation that the scheduler is not familiar with the raining distribution pattern of the construction site, inappropriate estimates of raining impacts could result in substantial difference between the planning schedule and the actual schedule. More and more construction projects are currently based on a calendar-day basis that the completion date may be already specified in the contract. The penalty for the 
delay of completion is typically about $0.3 \%$ of the total contract amount per day. It is essential for the contractor to prepare a decent and applicable schedule plan in avoiding such a huge penalty of schedule delays. This situation is even more significant when the contractor did not have much working experience about the distribution of rains in a particular city or area.

A good approach to overcome this problem is to incorporate the historical data of raining pattern in the scheduling planning process. With the historical data of raining pattern, the scheduler can adjust the duration of each activity in the network to yield a more probable completion date. In this way, the effects of rains could be independent from the duration estimation of each activity. The scheduler can assign an appropriate duration for each activity based on a no-rain condition while the effects of rains are adjusted by the historical data of raining pattern. In this approach, the scheduler can achieve a more applicable and accurate prediction of the completion date even though he did not have much sense about the distribution of rains of the construction site.

\section{Historic data of rains}

To built the computer-aided scheduling system, the historic data for raining distribution and patterns are needed. This data should be available and can be obtained from the Bureau of Weather. In Taiwan, the Bureau of Weather had made observations and records for rains, temperature, moisture content, as well as wind for each county since 1949. An updated records for the raining distribution and patterns in Taiwan was published in 1995 which contains the historic data of rains for the past 30 years. This source document provides basic information for the development of this study.

Although Taiwan is not big, the distribution of rains varies significantly in each county. In the northern Taiwan, there are about 100 to 180 raining days per year. However, in the southern Taiwan, there are only about 70 to 90 raining days per year. A raining day is defined as more than $1 \mathrm{~mm} /$ day of rains has been collected. The Bureau of Weather defines five degrees of rains according to the amount of rains been collected. They are $1 \mathrm{~mm} /$ day, $10 \mathrm{~mm} /$ day, $25 \mathrm{~mm} /$ day, $50 \mathrm{~mm} /$ day and $100 \mathrm{~mm}$ and up/day. The latter two will usually result in damages to the property and life of people.

Although the degrees of rains are defined, it is difficult for people to relate the amount of rains with the extend of raining. The $1 \mathrm{~mm} /$ day of rain is usually referred as a small rain which may interfere with some outdoor activities. The $10 \mathrm{~mm} /$ day of rain is called as a medium rain which may interfere with most of the outdoor activities. Also the rains may be accumulated on the ground before been distributed. The $25 \mathrm{~mm} /$ day of rain is referred as a big rain and most of the outdoor activities will stop. The $50 \mathrm{~mm} /$ day and $100 \mathrm{~mm} /$ day of rain usually come along with a storm and happen in mountain areas.

\section{System structure and features}

This study adopts the Ms-Project as the system mainframe for scheduling process. The Ms-Project is a readily available and useful software for project scheduling. Although some of the functional capability may not compete with other major scheduling tools such as P3 and OPENPLAN, the Ms-Project has become more and more popular due to its friendly interface, system application, as well as other advanced function features. The historic data of rains is build in a database format and link to the Ms-Project's input file. Other interfaces for importing data of the location of construction site and the start date of the project are programmed by Visual Basic to link with Ms-Project. All the functional capabilities of Ms-Project are still available for the system user.

This computer-aided scheduling system provides pull-down menu and interface for user to view and revise the historic data of rains if modification is needed. The system pull-down menu for incorporating the effects of rains in scheduling is shown in Figure 1.

\section{Schedule modification with rains}

To incorporate the effects of rains in scheduling, the user needs to specify the location of the construction site and the start date of the project. Then the system will automatically import the data and link to the associate database of rains. Since different degree of rains may have different schedule impact on various construction activities, this system defaults the $1 \mathrm{~mm}$ /day (small rain) in calculating the scheduling modification. The average numbers of rain days which the amount of rains is greater than $1 \mathrm{~mm} /$ day for the past 30 years in Taiwan are shown in Table 1 .

It is clear from Table 1 that the average numbers of rain days varies significantly in Taiwan. In north and eastern Taiwan, such as Keelung, Taipei, the average numbers of rain days is about 120 to 180 days. However, in the center and south Taiwan, such as Taichung and Kaoshung, there is only 70 to 80 rain days. Also the raining season varies in different areas. In north Taiwan, the summer is the dry season. Controversially, in center and south Taiwan, the winter is dry and the summer is the raining season. The variation of raining pattern should have essential impact on the schedule planning for construction. 


\section{Microsoft Project-Origin.MPP}

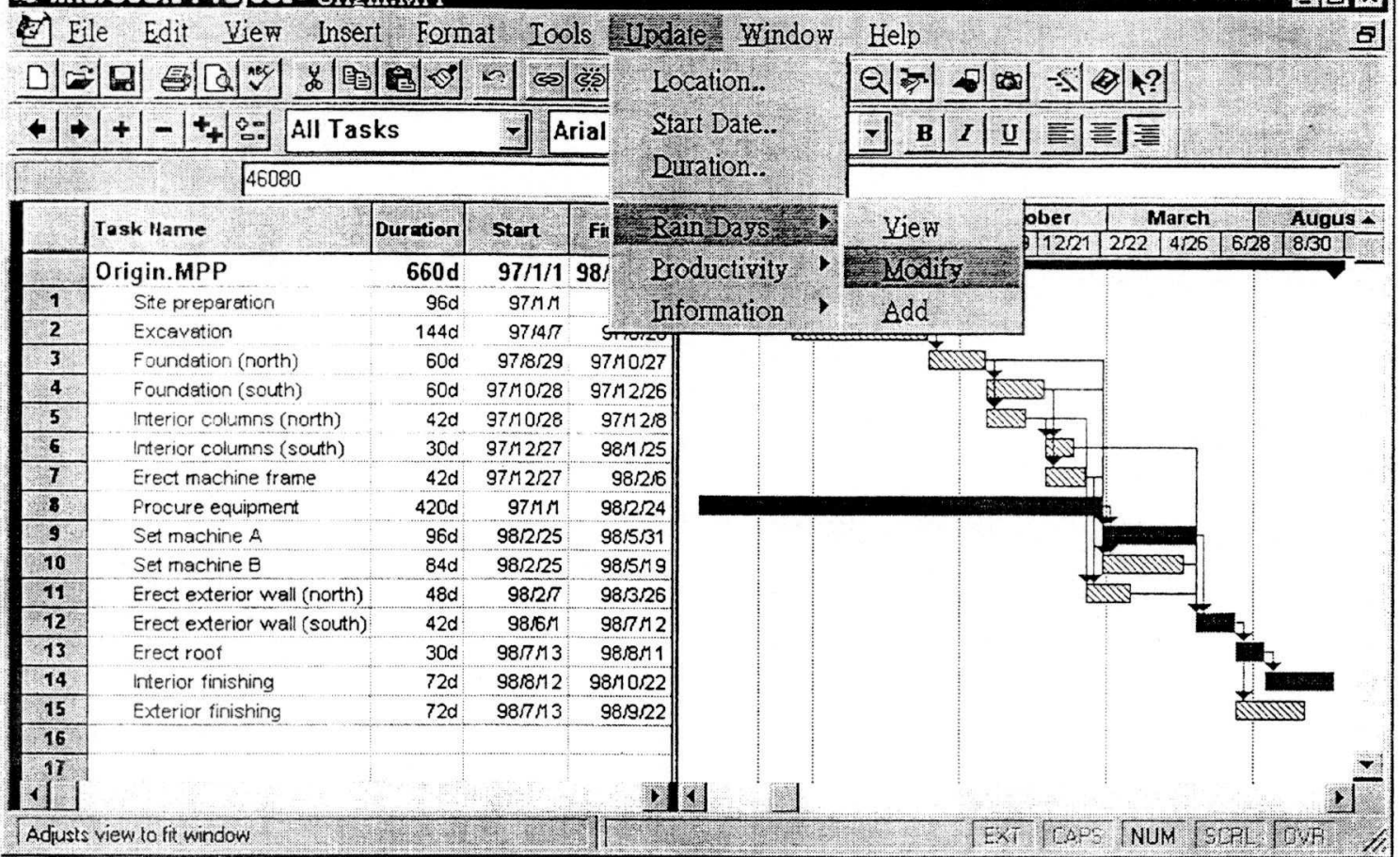

Figure 1 Pull-down menu for incorporating the effects of rains in scheduling

Table 1 Average number of rain days(1 mm/day and up, 1961 1990)

\begin{tabular}{|l|r|r|r|r|r|r|r|r|r|r|r|r|r|}
\hline \multicolumn{1}{|c|}{$\begin{array}{c}\text { Month } \\
\text { Location }\end{array}$} & 1 & 2 & 3 & 4 & 5 & 6 & 7 & 8 & 9 & 10 & 11 & 12 & Year \\
\hline \hline Danshaei & 12.7 & 12.3 & 13.5 & 10.1 & 11.4 & 10.4 & 6.8 & 7.9 & 9.9 & 9.5 & 11.0 & 11.1 & 126.6 \\
\hline Keelung & 17.3 & 17.3 & 17.3 & 12.7 & 15.4 & 12.5 & 6.3 & 8.4 & 12.4 & 13.6 & 16.9 & 16.8 & 166.9 \\
\hline Ilan & 13.3 & 14.0 & 14.0 & 11.2 & 15.9 & 13.1 & 7.0 & 10.0 & 14.1 & 16.2 & 17.4 & 14.5 & 160.7 \\
\hline Suao & 17.9 & 18.7 & 18.4 & 13.1 & 15.3 & 11.1 & 7.0 & 9.7 & 15.1 & 18.1 & 17.8 & 16.8 & 179.0 \\
\hline Taipei & 9.4 & 11.1 & 12.6 & 10.2 & 12.7 & 12.8 & 9.6 & 10.2 & 10.9 & 8.1 & 8.9 & 9.2 & 125.7 \\
\hline Hsinchu & 8.4 & 10.4 & 12.7 & 9.9 & 10.9 & 10.4 & 6.2 & 8.2 & 7.1 & 4.5 & 5.1 & 6.2 & 100.0 \\
\hline Wuchi & 3.9 & 6.9 & 9.3 & 8.4 & 8.5 & 9.1 & 6.1 & 8.5 & 4.3 & 1.1 & 2.2 & 2.3 & 70.6 \\
\hline Taichung & 4.4 & 6.2 & 8.0 & 7.1 & 9.5 & 11.8 & 9.4 & 11.2 & 6.4 & 1.7 & 2.4 & 2.7 & 80.8 \\
\hline Chaiee & 3.5 & 4.2 & 5.8 & 6.2 & 8.6 & 12.2 & 12.4 & 15.1 & 8.7 & 2.6 & 1.8 & 2.2 & 83.3 \\
\hline Tainan & 2.5 & 3.4 & 3.3 & 4.4 & 7.1 & 11.1 & 10.6 & 12.7 & 7.2 & 1.9 & 1.6 & 1.4 & 67.2 \\
\hline Kaoshung & 2.2 & 2.5 & 2.4 & 3.5 & 7.6 & 12.7 & 11.1 & 13.9 & 8.3 & 2.9 & 1.8 & 1.5 & 70.4 \\
\hline Hwalei & 11.2 & 12.6 & 12.6 & 11.9 & 14.4 & 11.6 & 7.0 & 9.3 & 11.0 & 11.1 & 10.6 & 8.5 & 131.8 \\
\hline Chunkung & 10.9 & 10.8 & 11.6 & 11.5 & 13.7 & 11.7 & 7.6 & 9.6 & 12.8 & 12.8 & 12.8 & 10.5 & 136.3 \\
\hline Taidong & 6.5 & 7.4 & 7.5 & 8.6 & 11.0 & 11.0 & 9.0 & 9.9 & 11.5 & 7.7 & 6.6 & 4.8 & 101.5 \\
\hline Daiwu & 8.5 & 8.6 & 7.2 & 8.5 & 11.1 & 13.3 & 11.3 & 13.2 & 13.6 & 10.2 & 8.6 & 6.6 & 120.7 \\
\hline Heinchun & 4.0 & 3.5 & 2.8 & 3.6 & 8.7 & 14.3 & 13.8 & 15.9 & 12.9 & 6.8 & 3.6 & 2.9 & 92.8 \\
\hline
\end{tabular}


The schedule impact of rains can be determined by the productivity loss due to the rains. A productivity loss index (P) was determined by interviews and survey of experienced schedulers and superintendents. The productivity loss index is defined between 1 to 0 . For activities which will completely stop due to the effects of rains, the productivity loss index is 1 . Typical activities include excavation, pouring concrete, and earth refill. For activities which would not be effected by rains, such as interior wall finishing, the productivity loss index will be 0 . Appropriate indices are also determined for other activities that productivity may be decreased by rains.

The schedule modification with rains are calculated as follow.

$$
\begin{aligned}
& D=D_{n}+D_{r} \\
& D_{r}=R \times P
\end{aligned}
$$

Where $D=$ Duration modification with rains

$\mathrm{D}_{\mathrm{n}}=$ Activity duration under no-rain basis

$\mathrm{D}_{\mathrm{r}}=$ Schedule delay due to rains

$\mathrm{R}=$ Average number of rain days

$\mathrm{P}=$ Productivity loss index for activity

The schedule modification above is quite straightforward and simple. The schedule delay due to rains will be added to the no-rain duration. The amount of schedule delay due to rains is proportionate to the average number of rain days and the productivity loss index. In this study, schedule modification is simplified to make the system easier to be build. In the real world, interrupted rains and continuous rains should have different impact on the productivity loss. Also the productivity loss index should be subjected to the amount of rains. In other words, for different degrees of rains, the productivity loss index should be different. In some cases, such as earthwork refill, the rains may not only decrease the productivity of the raining day itself, but also the productivity of several days after. It is because that the refill work must be done when the soil is totally dry. In this situation, more schedule delay need to be justified. All these problems require more study and investigation for determining proper amount of schedule modification.

\section{Case Simulation}

A case simulation for the computer aided scheduling system is shown as below. Table 2 show the activities in the network as well as the predecessors and the duration under a no-rain basis. The productivity loss index for each activity is also specified for the $1 \mathrm{~mm}$ /day amount of rains. These productivity loss indices are revisable and the user may update them under the system menu bar. The total duration for this sample project is 660 days under a no-rain basis. If the user specifies the project start date as Jan. 11997 without consideration of rains and site location, the project will be completed by Oct. 22 1998. The critical path for this project is activities 8-912-13-14 as shown in Figure 2.

Table 2 Activities of sample project

\begin{tabular}{|c|c|c|c|c|}
\hline$\#$ & Activity & Predecessors & $\begin{array}{c}\text { No-Rain } \\
\text { Duration }\end{array}$ & $\begin{array}{c}\text { Productivity } \\
\text { loss index }\end{array}$ \\
\hline \hline 1 & Site Preparation & -- & 96 & 0.3 \\
\hline 2 & Excavation & 1 & 144 & 1 \\
\hline 3 & Foundation (north) & 2 & 60 & 0.8 \\
\hline 4 & Foundation (south) & 3 & 60 & 0.8 \\
\hline 5 & Interior Column (north) & 3 & 42 & 0.2 \\
\hline 6 & Interior Column (south) & 4,5 & 30 & 0.2 \\
\hline 7 & Erect Machine Frame & 4 & 42 & 0.2 \\
\hline 8 & Procure Equipment & --- & 420 & 0 \\
\hline 9 & Set Machine A & $3,7,8$ & 96 & 0.1 \\
\hline 10 & Set Machine B & 4,8 & 84 & 0.1 \\
\hline 11 & Erect Exterior Wall (north) & 5,7 & 48 & 0.5 \\
\hline 12 & Erect Exterior Wall (south) & $6,9,10,11$ & 42 & 0.5 \\
\hline 13 & Erect Roof & 12 & 30 & 0.6 \\
\hline 14 & Interior Finishing & 13 & 72 & 0 \\
\hline 15 & Exterior Finishing & 12 & 72 & 1 \\
\hline
\end{tabular}




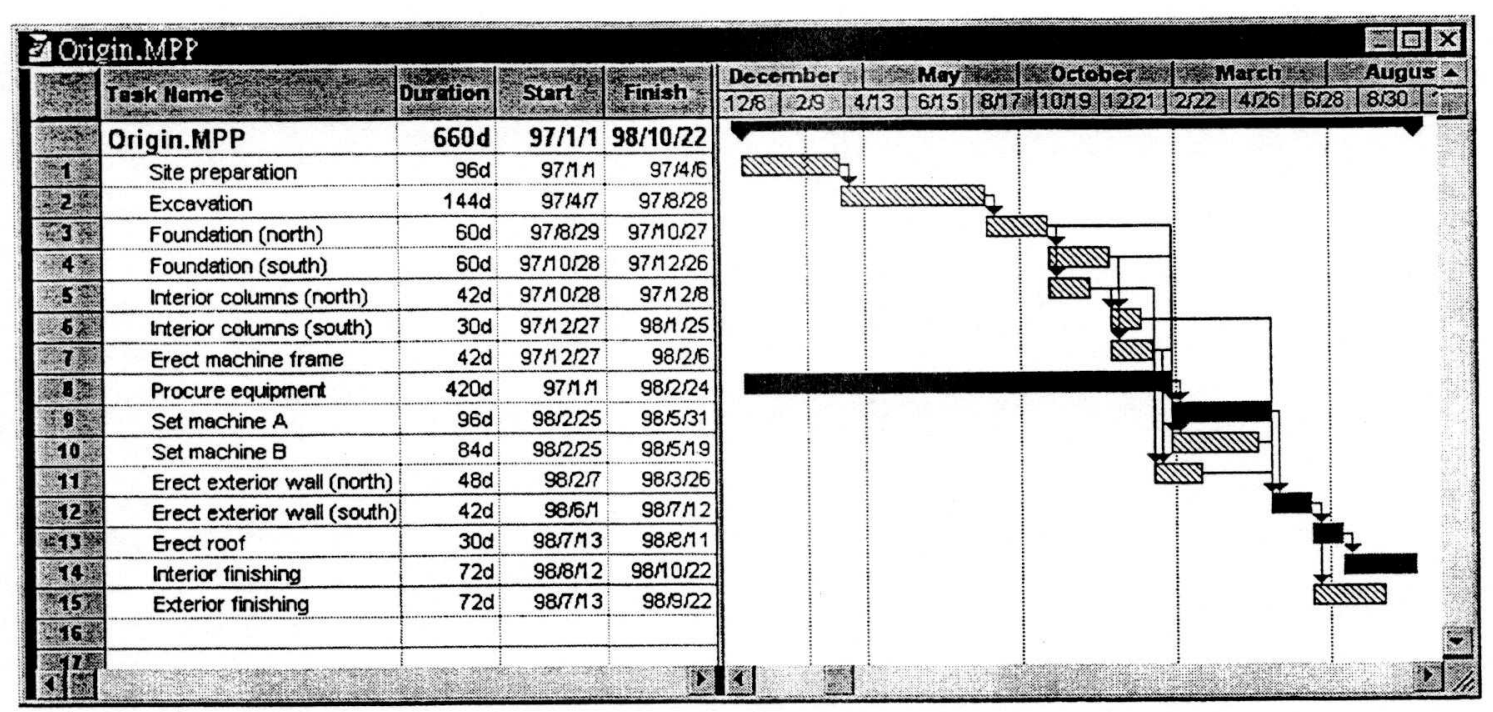

Figure 2 Schedule planning with no-rain basis

Four simulation tests are conducted to show the outcomes of the scheduling results by this computer-aided system for incorporating the effects of rains. The Taichung city is located in the center Taiwan which the effects of rain is not significant and the summer is the raining season. Comparatively, the Keelung city is located in north Taiwan which the effects of rain is significant and the summer is the dry season.
1. Location: Taichung, Start date: Jan. 11997

2. Location: Taichung, Start date: June. 11997

3. Location: Keelung, Start date: Jan. 11997

4. Location: Keelung, Start date: June. 11997

The scheduling results are shown in Figures 3 to 6 respectively.

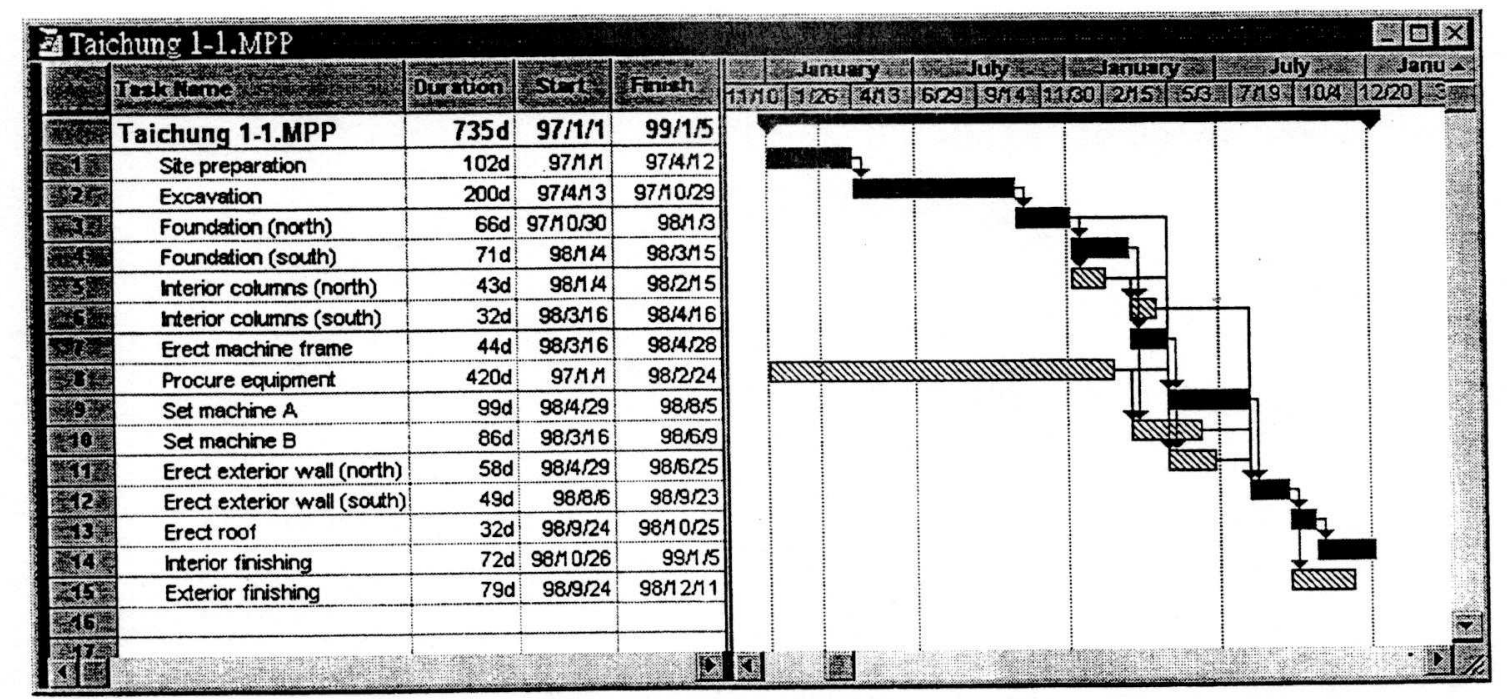

Figure 3 Schedule planning for Taichung, Start date: Jan. 11997 


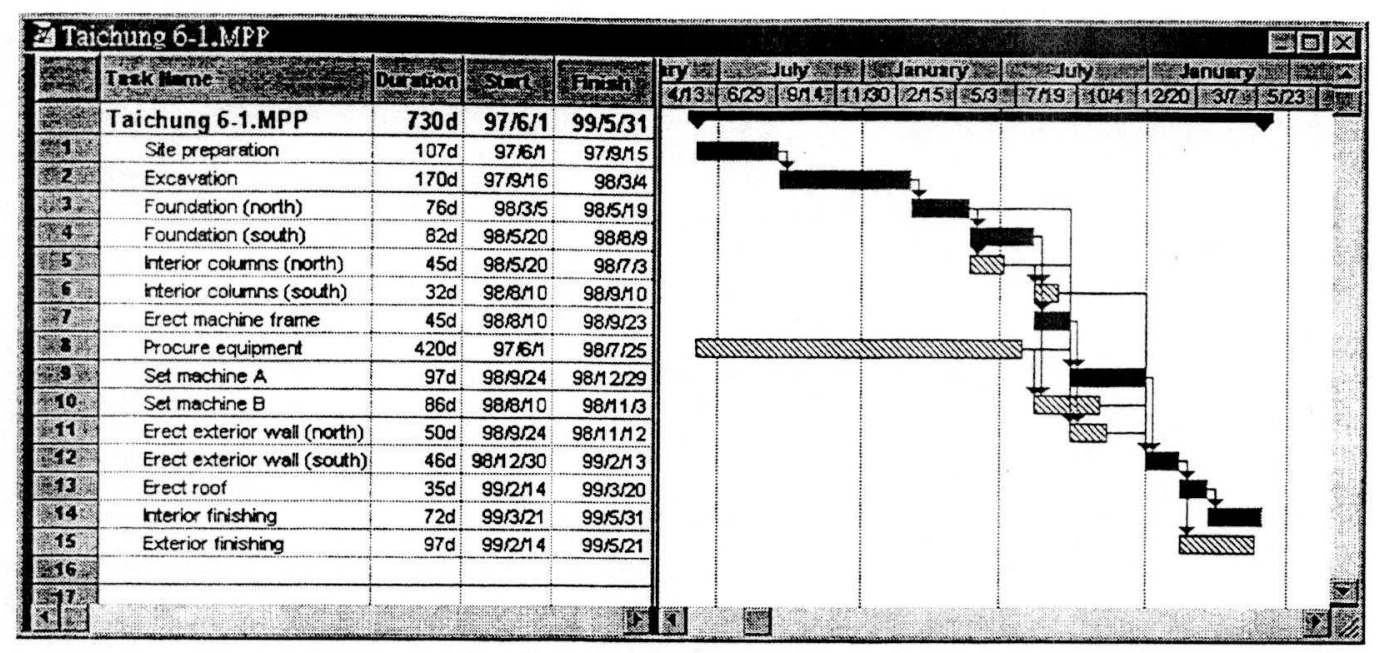

Figure 4 Schedule planning for Taichung, Start date: June. 11997

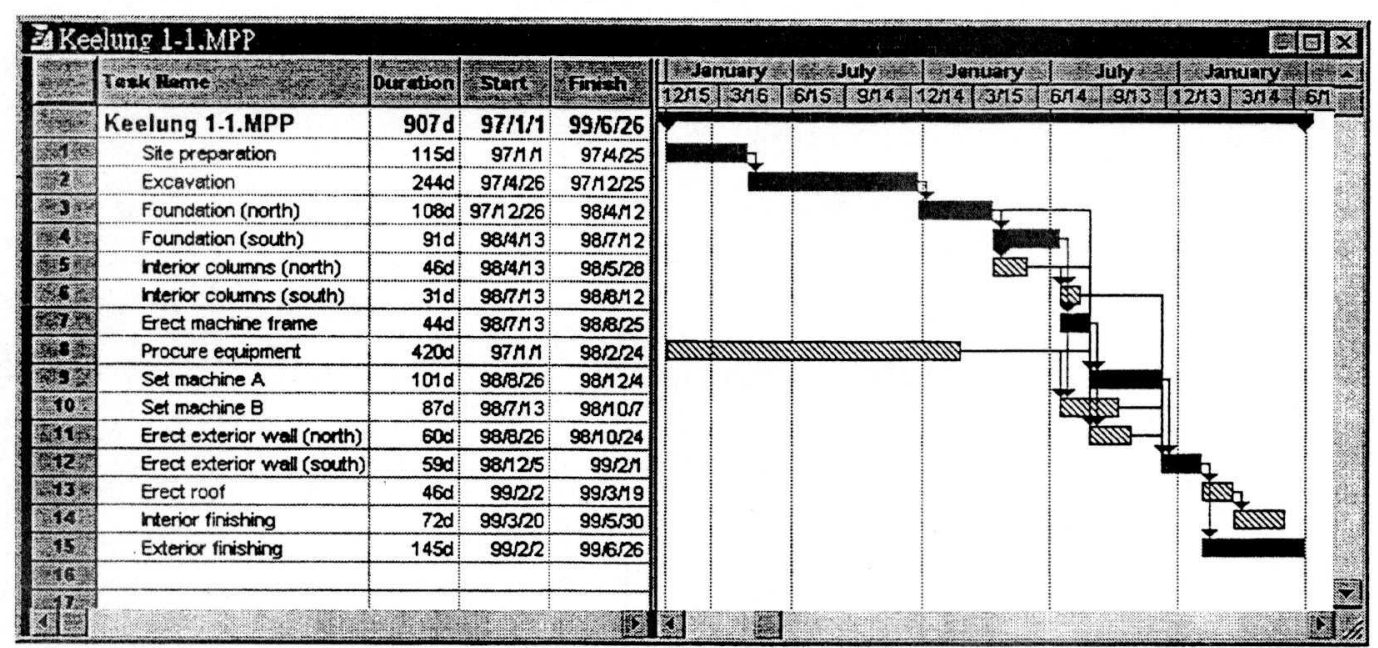

Figure 5 Schedule planning for Keelung, Start date: Jan. 11997

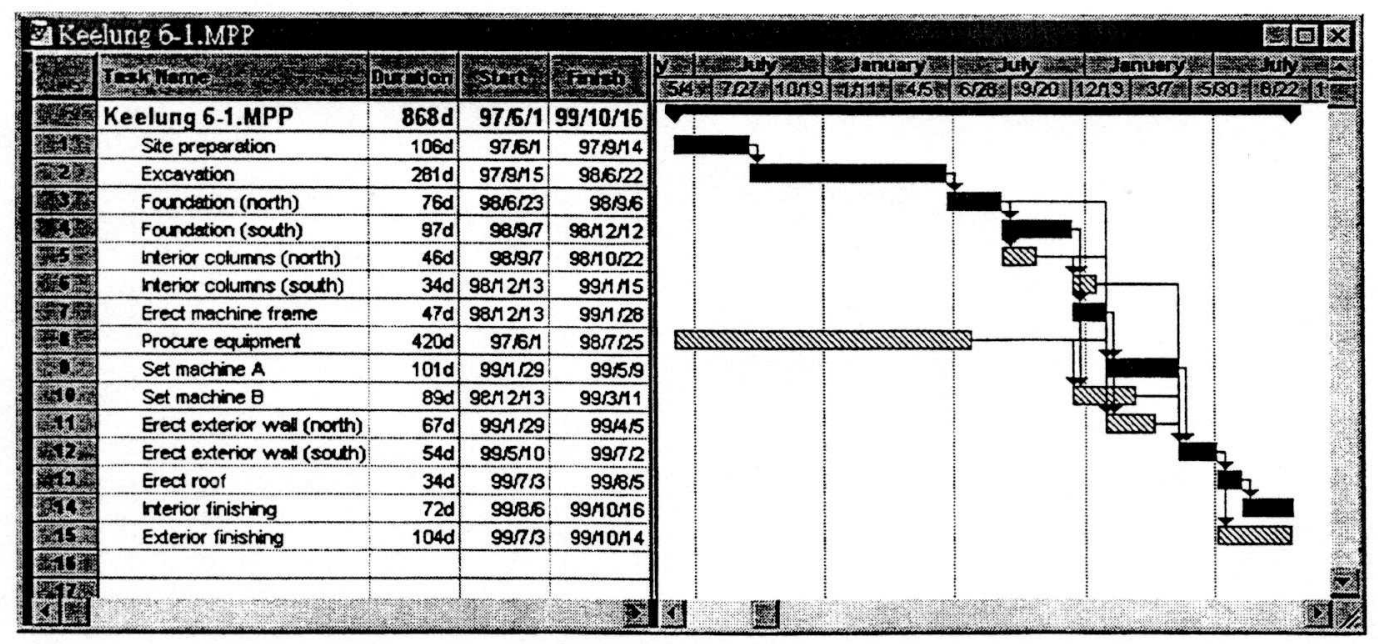

Figure 6 Schedule planning for Keelung, Start date: June. 11997 
Due to the effects of rains, the schedule planning yields various results in figures 3 to 6 . If the project is to be built in the Taichung with start date in January 1 1997, the effects of rains will cause the completion date become January 5 1999(total duration 735 days). If the start date is shifted to June 1 , the raining season in Taichung, the completion date will delayed until May 31 1999(total duration 730 days). On the other hand, if this project is to be built in the Keelung with start date in January 11997 , due to the significant effects of rain, the completion date would be June 26 1999(total duration 907 days). However, if the start date is shifted to June 1 , the dry season in Keelung, then the completion date of this project would be Oct. 16 1999(total duration 868 days). The differences of the results are due to the substantial raining season impacts on the excavation and foundation works as well as the exterior finishing of the project. Another impact caused by the effects of rains is the change of critical path. The original critical path for this project is activities 8-9-12-13-14 with no-rain basis. However, for the four simulation tests, the critical path is shifted to activities 1-2-3-4-7-9-12-13-14.

\section{Conclusion}

This computer aided scheduling system incorporates the MS-Project with a weather data base that contains the distribution of rains for the past 30 years in each county of Taiwan. In the schedule planning process, the scheduler inputs the logic sequences and duration of each activity in the network based on no-rain condition. Then, the system will requires the user to locate the construction site and specify the start date of the project. These two inputs will link the network calculation with the weather data base automatically. Then, a proper amount of schedule delays due to the distribution and effects of rains can be yield and combined with the no-rain basis to achieve the final completion date.

Traditionally, the schedule planning process requires the scheduler to make estimates of the effects of rains based on previous working experience. Substantial amount of schedule delays may occur due to the inappropriate estimates of the effects of rains. While the historical data of raining pattern and geography location are available from the Bureau of Weather, the effects of rains can be independent from the schedule estimate process. This computer aided scheduling system incorporates the historical data of raining pattern in the scheduling process and yields a more applicable and reliable result for schedule planning.

\section{References}

1. AbouRizk, S. M., and Halpin, D. W. (1992), "Statistical Properties of construction duration data" $J$. of the Constr. Eng. and Mgmt., ASCE, 118(3), 525-544.

2. Ahuja, H. N. and Nandakumar, V. (1985), "Simulation Model to Forecast Project Completion Time", J. of the Constr. Eng. and Mgmt., ASCE, 111(4), 325-342.

3. Alsugair, A. A.and Chang, D. Y., (1994), "A Goal Driven Approach to Discrete Event Simulation", Conference of Computing in Civil Engineering, 515-522.

4. Ayyub, B. M., and Halder, A. (1984), "Project scheduling using fuzzy set concept" $J$. of the Constr. Eng. and Mgmt., ASCE, 110(2), 189-204.

5. Dize, C. F., and Hadipriono, F.C. (1993), "Nondeterministic networking methods" J. of the Constr. Eng. and Mgmt., ASCE, 119(1), 40-57.

6. Law, A.M., and Kelton W. D. (1982), Simulation modeling and analysis. McGraw-Hill Book Co., New York, N. Y.

7. Moder, J. J., Phillips, C. R., and Davis, E. W. (1983), Project management with CPM, PERT, and precedence diagram. Van Nostrand Company Inc., New York.

8. Moselhi, O., and Lorterapong, P. (1995), "Fuzzy vs. probabilistic scheduling" Automation and Robotics in Construction XII, 441-448.

9. Oberlender, G. D. (1993), Project management for engineering and construction. McGraw-Hill Book Co., New York, N. Y.

10. O'Brien, J.' J. (1984), CPM in construction management, McGraw-Hill Book Co., New York, N. Y.

11. Paulson, B.C.and Koo, C.C.(1986), "Microcomputer Construction Operations Simulation", Conference of Computing in Civil Engineering, 410-423.

12. Smith, G. R., and Hancher, D. E. (1989), "Estimating precipitation impacts for scheduling" $J$. of the Constr. Eng. and Mgmt., ASCE, 115(4), 189-204.

13. Stefan, C., and Jerzy, K. (1981), "The use of fuzzy variable in PERT", Fuzzy Sets and Systems, 5, 11-19.

14. Touran, A., and Wiser, E. P. (1992), "Monte carlo technique with corrllated random variables " $J$. of the Constr. Eng. and Mgmt., ASCE, 118(2), 258-272.

15. Wu, W. K., and Hadipriono, F. C. (1994), "Fuzzy modus deduction technique for construction scheduling" $J$. of the Constr. Eng. and Mgmt., ASCE, 120(1), 162-179. 